\title{
An Accurate Measurement Method for Tension Force of Short Cable by Additional Mass Block
}

\author{
Shuichang Li $\left(\mathbb{D},{ }^{1}\right.$ Longlin Wang $\mathbb{D}^{2,3}$ Hua Wang ${ }^{2},{ }^{3,4}$ Peihua Shi $\mathbb{D}^{3}$, Riyan Lan $\mathbb{D}^{5,}, 6$ \\ Changxia $W u\left(\mathbb{D},{ }^{3}\right.$ and Xirui Wang $\mathbb{D}^{3}$ \\ ${ }^{1}$ Guangxi Nantian Expressway Co.,Ltd., Nanning 530007, China \\ ${ }^{2}$ Southeast University, Nanjing 211189, China \\ ${ }^{3}$ Guangxi Transportation Science and Technology Group Co.,Ltd., Nanning 530007, China \\ ${ }^{4}$ Guangxi Beibu Gulf Investment Group Co.,Ltd., Nanning 530029, China \\ ${ }^{5}$ Central South University, Changsha 410012, China \\ ${ }^{6}$ Guangxi Xinfazhan Communication Group Co.,Ltd., Nanning 530029, China
}

Correspondence should be addressed to Hua Wang; wanghua15@mails.jlu.edu.cn

Received 3 December 2020; Revised 5 January 2021; Accepted 16 January 2021; Published 27 January 2021

Academic Editor: Qinglin Guo

Copyright (C) 2021 Shuichang Li et al. This is an open access article distributed under the Creative Commons Attribution License, which permits unrestricted use, distribution, and reproduction in any medium, provided the original work is properly cited.

\begin{abstract}
The equivalent effective length parameter is introduced into the vibration equation of short cable; that is, the boundary condition that affects the test accuracy of short cable force is equivalent to the calculated length of cable. By attaching an additional mass block to the cable, new parameters are introduced to identify the tension force. Vibration differential equations are established for cable with and without addition mass block, taking new parameters into account, such as equivalent effective length and added mass. By solving the equations using the RITZ method, the analytical relationship between the natural frequency of cable and equivalent effective length before and after a mass block is added can be developed. It can also develop an analytical method to identify the equivalent effective length depending on whether the added mass block is attached. Then, tension force of short length cable can be evaluated by measuring its natural frequency based on equivalent effective length. The method is verified by field tests. The tests results indicate the new method mentioned in this paper is going to largely improve the accuracy of tension force measurement of short length cable.
\end{abstract}

\section{Introduction}

In recent years, China's infrastructure has made rapid development; especially in the transportation infrastructure, it has made remarkable achievements [1-3]. In order to ensure the safe operation of traffic infrastructure, nondestructive testing technology has been paid more and more attention $[4,5]$. In the long-span bridges that have been built, the cable-type bridges occupy a very important proportion. Among them, the cable is an important force transmission component. No matter in the design, construction, or maintenance stage, the cable force is a very important parameter $[6,7]$.

The common methods used in cable force tests are the pressure sensor method and frequency method. The pressure sensor method can only test the cable force with the pressure sensor installed in advance in the construction and cannot be used without sensors after the bridge is completed [4]. The frequency method [8-11] is widely used because of its simple equipment, high reliability, and accuracy of cable force results, which can meet the requirements of repeated tests in engineering. The main steps are as follows: the natural frequency of the cable is firstly analyzed by vibration signal of the cable; next one brings the natural frequency into the relationship between the cable force and the natural frequency and then obtains the cable force. It should be noted that the relationship between the cable force and the natural frequency in the existing technology is derived based on the string tension. For long cable (the ratio of cable length to diameter is more than 200 times), the cable force obtained 
by this relationship can meet the requirements of the project. However, for the short cable, the error of cable force may be very large, and even the wrong result will be obtained. It is mainly due to the anchorage conditions, casing, shock absorber, cable stiffness, and other factors that will have a greater impact on cable frequency. How to accurately test the short cable force is always an unsolved engineering problem. In order to solve this problem, many scholars have proposed some approximate algorithms or solved this problem by the finite element method [12] and the difference method [13].

In 1996, Zui et al. [14] put forward a practical formula, which can be used to calculate the cable force using the widely used fundamental frequency and the second-order frequency. In 1998, Mehrabi and Tabatabai [15] proposed a practical formula that can consider the cable sag effect and bending stiffness, which assumes that both ends of the cable are consolidated. The formula has high accuracy for cables with a sag parameter less than 3.1 and a bending stiffness parameter greater than 50. Fang and Wang [16] obtained the numerical relationship among flexural rigidity, length, linear density, and vibration frequency based on the transverse vibration equation of the beam under axial tension. In 2002, Zui et al. [17] proposed the Kalman filtering method to identify the tension and bending stiffness of the suspender according to the cable vibration caused by an external force. Roman et al. [18] proposed that the changing trend of each frequency should be considered in the calculation of cable force, so as to achieve the consistency between the highorder frequency value and the low-order frequency value and meet the shortcomings that the low-order frequency may be difficult to measure in the actual engineering. Kim and Park [19] proposed a parameter identification method based on frequency sensitivity correction to identify the bending stiffness and cable force of the cable. Through the comparison of the calculation results of three different methods, i.e., finite element method, experiment, and example, it shows that the cable force calculated by this method has high accuracy. In 2010, Park et al. [20] proposed a parameter identification method based on the suspension bridge, which can identify bending stiffness and tensile stiffness parameters. In 2015, Kyu-Sik et al. [21] proposed a systematic identification method for the finite element model to avoid the occurrence of large deviation of the short cable and proved that the finite element model is more accurate than the calculation result of the practical formula on the basis of parameter identification through examples. Yan et al. [22] established an innovative framework for the cable force estimation considering complex boundary conditions, from the perspective of the zero-amplitude points of cable mode shapes. Considering the complexity of the vibration-based cable tension estimation, Ehsan et al. [23] proposed a simple novel framework to estimate the cable tension based on artificial neural networks and verified the accuracy of the method through the Ironton-Russell Bridge.

It can be seen from the existing research work that there is a good solution to the identification of the cable force for long cable at present, while for short cable, researchers usually use the finite element method combined with parameter identification technology to consider the influence of bending stiffness, boundary conditions, etc., which has a high technical requirement for engineers and is not conducive to the engineering application. By analyzing on vibration characteristics of cables, a new parameter named equivalent effective length is introduced to solve the issue in this paper. There will be more parameters to be measured by adding added mass block on cables in order to combine the concept of equivalent effective length and parameter of an added mass block. The analytical method for calculating equivalent effective length is established by measuring the difference of vibration frequency of cable before and after addition mass block is applied. Then, tension force of short length cable can be identified based on the equivalent effective length and measured vibration frequency. Finally, the reliability and practicability of this method are verified by practical engineering application.

\section{Equivalence of Effective Cable Length}

Nowadays, one of the most popular and convenient ways to identify cable tension in engineering projects depends on the measurement of the cable's vibration frequency and the following calculation. For those cables which are not equipped with a pressure sensor or other instruments, frequency method is the most efficient and economical way during the service stage. The theory is to simplify a cable as a simply supported cable, where $L$ is the effective length, $T_{0}$ is the cable tension, and EI is the bending stiffness of cable. The simplified model is shown in Figure 1.

Figure 2 shows a microscopic mechanics model of a cable with transverse vibration, where $y(x, t)$ is the horizontal movement varied with location $x$ and time $t, m$ is the weight of cable per unit length, $M$ is the bending moment, and $V$ is the shear force. Here, the bending stiffness of cable is taken into consideration.

The vibration equation can be developed based on the equilibrium of force and moment:

$$
E I \frac{\partial^{4} y(x, t)}{\partial x^{4}}+m \frac{\partial^{2} y(x, t)}{\partial t^{2}}-T_{0} \frac{\partial^{2} y(x, t)}{\partial x^{2}}=0 .
$$

Having solved equation (1) by the Galerkin procedure, the natural frequency of cable is given as

$$
\omega_{n}=\sqrt{\frac{E I}{m}\left(\frac{n \pi}{L}\right)^{4}+\frac{T_{0}}{\rho A}\left(\frac{n \pi}{L}\right)^{2}} \quad(n=1,2,3, \ldots),
$$

where $\omega_{n}$ is the $n$-order natural frequency.

From equation (2), one can solve the tension force once the natural frequency of cable is measured since bending stiffness of cable $E I$, weight per unit length $m$, and effective length $L$ are known. Bending stiffness EI and mass per unit length $m$ can be known right after cable installation. For effective length $L$, it is determined by boundary conditions of cable such as distance between two anchoring points or damper conditions at the two ends. For cable with long length, the ratio of influence in terms of boundary conditions on effective length $L$ is not so large so that the accuracy of tension force measurement is still acceptable. However, 


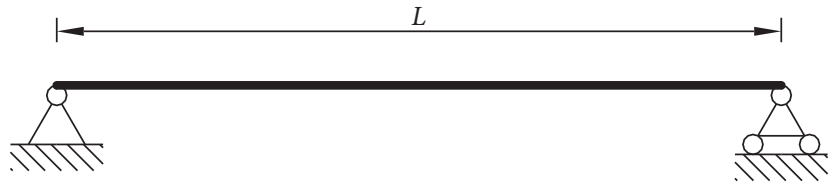

FIgURE 1: Simplified mechanics model of a cable.

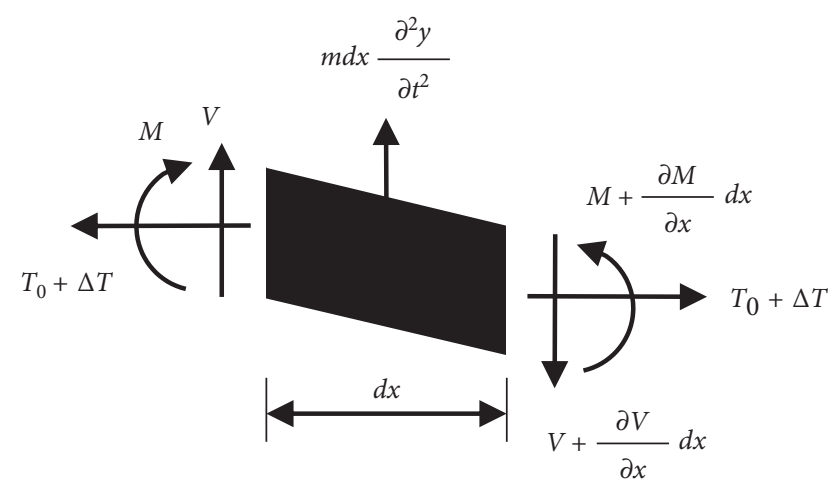

Figure 2: A microscopic mechanics model of a vertical stretched cable with consideration of bending stiffness.

when cable length becomes short, boundary conditions will have a large effect on the accuracy of cable tension measurement. And the error and accuracy are not accepted, sometimes even lead to misjudgment.

From the analysis above, for short length cable, the main factor influencing the accuracy of tension force measurement by using the frequency method is the boundary conditions. The effect can be equivalent to the influence on effective length. Now define $L$ as the distance between two anchoring points, two dampers are installed, respectively, from anchoring point with distance $d$, and the stiffness of damper is $k$. The force diagram of cable is simplified as Figure 3.

From the mechanical equilibrium of force and moment, one can obtain the vibration equilibrium of cable:

$$
E I \frac{\partial^{4} y(x, t)}{\partial x^{4}}+m \frac{\partial^{2} y(x, t)}{\partial t^{2}}-T \frac{\partial^{2} y(x, t)}{\partial x^{2}}+k y(x, t) \cdot \delta_{1}(x-d)++k y(x, t) \cdot \delta_{2}(x-d+L)=0
$$

where $E I$ is the stiffness of cable, $m$ is the cable weight per unit length, $T$ is the tension force, and $\delta_{1}(x-d)$ and $\delta_{2}(x-$ $d+L$ ) are the Dirac equation, i.e.,

$$
\begin{aligned}
\delta_{1}(x-d) & = \begin{cases}1, & x=d, \\
0, & x \neq d,\end{cases} \\
\delta_{2}(x-d+L) & = \begin{cases}1, & x=L-d, \\
0, & x \neq L-d .\end{cases}
\end{aligned}
$$

Equation of free vibration for cable is

$$
y(x, t)=\phi(x) \sin (\omega t+\theta),
$$

where $\phi(x)$ is the vibration function of cable, $\omega$ is the natural frequency of cable, and $\theta$ is the phase angle.
By using the RITZ method, the total kinetic energy of cable vibration at a moment is

$$
E_{k}=\frac{1}{2} \int_{0}^{L} m\left(\frac{\partial y}{\partial t}\right)^{2} \mathrm{~d} x=\frac{1}{2} m \omega^{2} \cos ^{2}(\omega t+\theta) \int_{0}^{L}[\phi(x)]^{2} \mathrm{~d} x .
$$

From the equation above, one can get the maximum total kinetic energy

$$
E_{k \max }=\frac{1}{2} m \omega^{2} \int_{0}^{L}[\phi(x)]^{2} d x .
$$

And the total potential energy of cable at a moment is

$$
\begin{aligned}
V_{k}= & \frac{1}{2} \int_{0}^{L} E I\left(\frac{\partial^{2} y}{\partial x}\right)^{2} \mathrm{~d} x+\frac{1}{2} \int_{0}^{L} T\left(\frac{\partial y}{\partial x}\right)^{2} \mathrm{~d} x+\frac{1}{2} k[y(d, t)]^{2}+\frac{1}{2} k[y(L-d, t)]^{2} \\
= & \frac{1}{2} E I \sin ^{2}(\omega t+\theta) \int_{0}^{L}\left[\phi^{\prime \prime}(x)\right]^{2} \mathrm{~d} x+\frac{1}{2} T \sin ^{2}(\omega t+\theta) \int_{0}^{L}\left[\phi^{\prime}(x)\right]^{2} \mathrm{~d} x+\frac{1}{2} k \sin ^{2}(\omega t+\theta)[\phi(d)]^{2} \\
& +\frac{1}{2} k \sin ^{2}(\omega t+\theta)[\phi(L-d)]^{2} .
\end{aligned}
$$




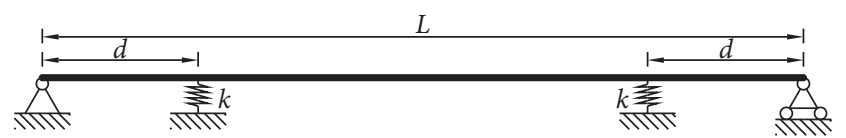

FIGURE 3: Simplified force diagram of cable influenced by stiffness of damper.

From the equation above, the maximum total potential energy could be obtained as follows:

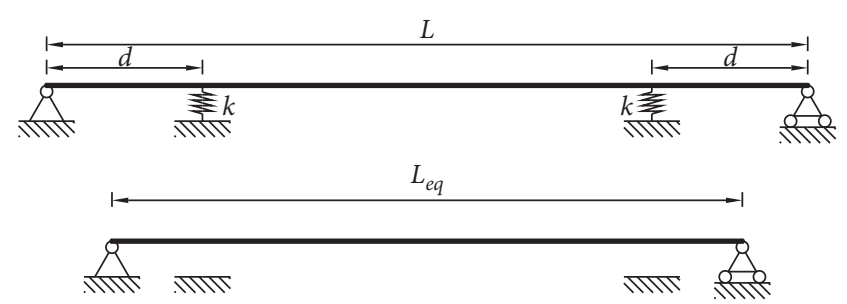

FIgURE 4: Equivalent model of cable.

$$
V_{k \max }=\frac{1}{2} E I \int_{0}^{L}\left[\phi^{\prime \prime}(x)\right]^{2} \mathrm{~d} x+\frac{1}{2} T \int_{0}^{L}\left[\phi^{\prime}(x)\right]^{2} \mathrm{~d} x+\frac{1}{2} k[\phi(d)]^{2}+\frac{1}{2} k[\phi(L-d)]^{2} .
$$

When the stiffness of damper is small, vibration mode of cable can be approximated as a vibration of a simply supported beam, which is

$$
\phi(x)=\sin \left(\frac{n \pi x}{L}\right) .
$$

According to the RITZ method, for cable vibration, the maximum total kinetic energy is equal to the maximum potential energy:

$$
E_{k \max }=V_{k \max }
$$

Based on equations (7) and (9), one can solve the natural frequency of cable

$$
\omega^{2}=\frac{E I \int_{0}^{L}\left[\phi^{\prime \prime}(x)\right]^{2} \mathrm{~d} x+T \int_{0}^{L}\left[\phi^{\prime}(x)\right]^{2} \mathrm{~d} x+k[\phi(d)]^{2}+k[\phi(L-d)]^{2}}{m \int_{0}^{L}[\phi(x)]^{2} \mathrm{~d} x} .
$$

Taking equations (10) into (12) has

$$
\omega^{2}=\frac{E I}{m}\left(\frac{n \pi}{L}\right)^{4}+\frac{T}{m}\left(\frac{n \pi}{L}\right)^{2}+\frac{4 k}{m L} \sin ^{2}\left(\frac{n \pi d}{L}\right)
$$

where $\sin ^{2}(n \pi d / L)$ is a constant. Define $\beta=\sin ^{2}(n \pi d / L)$, and (13) becomes

$$
\omega^{2}=\frac{E I}{m}\left(\frac{n \pi}{L}\right)^{4}+\frac{T}{m}\left(\frac{n \pi}{L}\right)^{2}+\frac{4 k \beta}{m L} .
$$

Now, one can transform the force diagram in Figure 3 into a new equivalent force diagram with an equivalent effective length $L_{e q}$ of pin-supported cable, as shown in Figure 4.

Then, the natural frequency of cable after equivalence is

$$
\omega^{2}=\frac{E I}{m}\left(\frac{n \pi}{L_{e q}}\right)^{4}+\frac{T}{m}\left(\frac{n \pi}{L_{e q}}\right)^{2}
$$

Since the natural frequency does not change before and after equivalence, by taking equations (14) and (15) into consideration, one has

$$
\frac{E I}{m}\left(\frac{n \pi}{L}\right)^{4}+\frac{T}{m}\left(\frac{n \pi}{L}\right)^{2}+\frac{4 k \beta}{m L}=\frac{E I}{m}\left(\frac{n \pi}{L_{e q}}\right)^{4}+\frac{T}{m}\left(\frac{n \pi}{L_{e q}}\right)^{2} .
$$

Here, if the influence of bending stiff of cable is ignored, one can derive the relationship between original length and equivalent effective length of cable:

$$
L_{e q}=L \sqrt{\frac{1}{1+\left(4 L k \beta / T n^{2} \pi^{2}\right)}}
$$

From the above equation, it is obvious that the equivalent length of cable is shorter compared to the original cable length because the effect of damper stiffness. Based on the theoretical derivation above, for a cable with a damper, its effective length can be equivalent by using an equivalent effective length to identify the cable tension force.

\section{Using Added Mass to Identify the Effective Length of Short Length Cable}

In equation (14), stiffness of cable $E I$ and mass per unit length $m$ are determined by design, and natural frequency of cable $\omega_{n}$ can be measured by vibration testing instrument. Therefore, it is only necessary to figure out the equivalent effective length $L_{e q}$ in order to obtain the cable tension force $T$ based on measured vibration frequency $\omega_{n}$.

To figure out the $L_{e q}$, an added mass $M$ is applied on cable on purpose, away from bottom end of cable by a distance $L_{m}$. Then, the cable can be simplified as the model shown in Figure 5, where $L_{m}^{\prime}=L_{m}-\left(L-L_{e q} / 2\right)$.

Here, the vibration equilibrium of cable becomes

$$
E I \frac{\partial^{4} y(x, t)}{\partial x^{4}}+\left[m+M \delta\left(x-L_{m}^{\prime}\right)\right] \frac{\partial^{2} y(x, t)}{\partial t^{2}}-T \frac{\partial^{2} y(x, t)}{\partial x^{2}}=0
$$




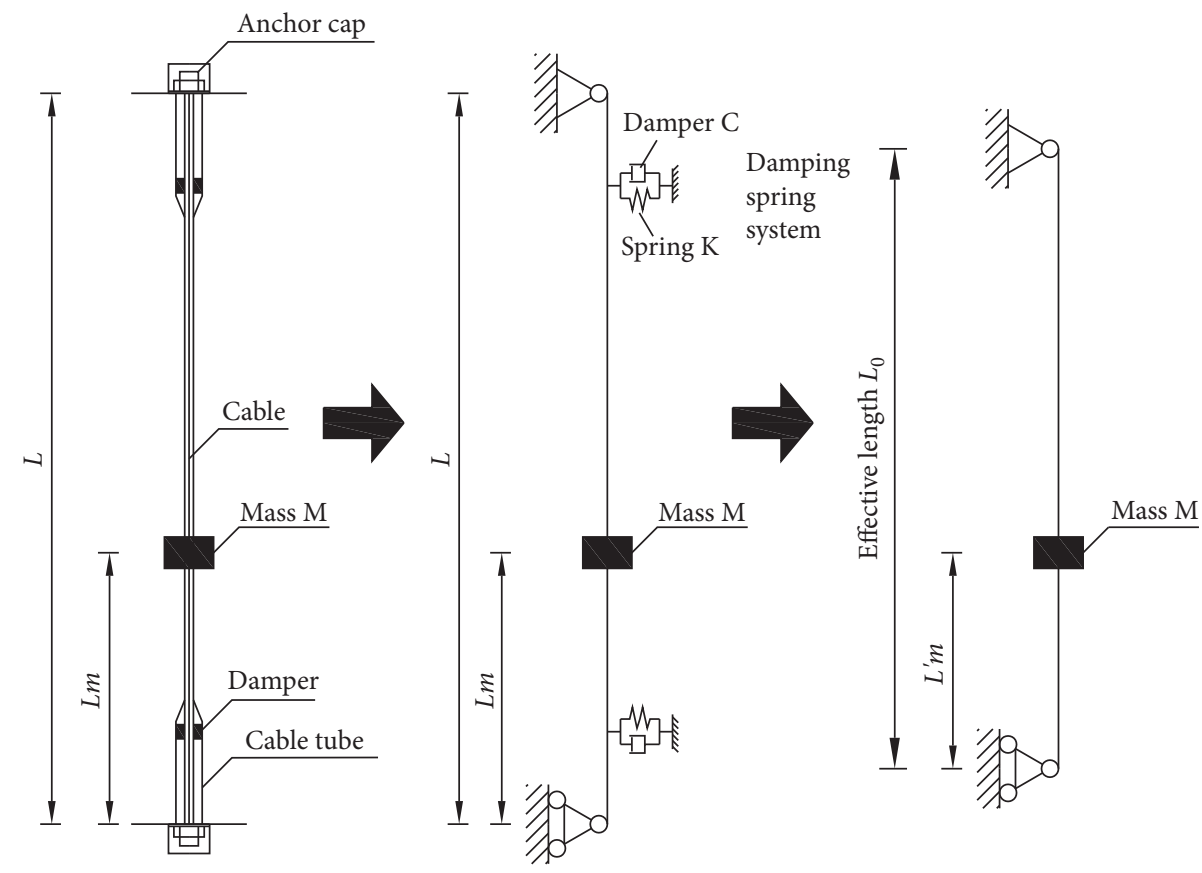

FIgURE 5: Simplified diagram of cable with added mass.

where $\delta\left(x-L_{m}^{\prime}\right)= \begin{cases}1 & x=L_{m}^{\prime} \\ 0 & x \neq L_{m}^{\prime}\end{cases}$

The free vibration equation of cable might be defined as

$$
y(x, t)=\phi(x) \sin \left(\omega_{m} t+\theta\right),
$$

where $\phi(x)$ is the vibration model function, $\omega_{m}$ is the natural frequency of cable after added mass block is applied, and $\theta$ is the phase angle.

Also, use the RITZ method to solve the vibration equilibrium of cable in equation (19). Now the total kinetic energy of cable vibration at a moment is

$$
\begin{aligned}
E_{k} & =\frac{1}{2} \int_{0}^{L} m\left(\frac{\partial y}{\partial t}\right)^{2} \mathrm{~d} x+\frac{1}{2} M\left(\frac{\partial y\left(L_{m}^{\prime}, t\right)}{\partial t}\right)^{2} \\
& =\frac{1}{2} m \omega_{m}^{2} \cos ^{2}\left(\omega_{m} t+\theta\right) \int_{0}^{L}[\phi(x)]^{2} \mathrm{~d} x+\frac{1}{2} M \omega_{m}^{2} \cos ^{2}\left(\omega_{m} t+\theta\right)\left[\phi\left(L_{m}^{\prime}\right)\right]^{2}
\end{aligned}
$$

Then, the maximum total kinetic energy $E_{k \max }$ is

$$
E_{k \max }=\frac{1}{2} m \omega_{m}^{2} \int_{0}^{L}[\phi(x)]^{2} \mathrm{~d} x+\frac{1}{2} M \omega_{m}^{2}\left[\phi\left(L_{m}^{\prime}\right)\right]^{2} .
$$

And the total potential energy of cable vibration at a moment is

$$
\begin{aligned}
V_{k} & =\frac{1}{2} \int_{0}^{L} E I\left(\frac{\partial^{2} y}{\partial x}\right)^{2} \mathrm{~d} x+\frac{1}{2} \int_{0}^{L} T\left(\frac{\partial y}{\partial x}\right)^{2} \mathrm{~d} x \\
& =\frac{1}{2} E I \sin ^{2}\left(\omega_{m} t+\theta\right) \int_{0}^{L}\left[\phi^{\prime \prime}(x)\right]^{2} \mathrm{~d} x+\frac{1}{2} T \sin ^{2}\left(\omega_{m} t+\theta\right) \int_{0}^{L}\left[\phi^{\prime}(x)\right]^{2} \mathrm{~d} x .
\end{aligned}
$$

Then, the maximum total potential energy is

$$
V_{k \max }=\frac{1}{2} E I \int_{0}^{L}\left[\phi^{\prime \prime}(x)\right]^{2} \mathrm{~d} x+\frac{1}{2} T \int_{0}^{L}\left[\phi^{\prime}(x)\right]^{2} \mathrm{~d} x .
$$

When the added mass is small, vibration mode of cable can be approximated as the vibration of a simply supported beam, which is 


$$
\phi(x)=\sin \left(\frac{n \pi x}{L_{e q}}\right) .
$$

According to the RITZ method, for cable vibration, the maximum total kinetic energy is equal to the maximum potential energy:

$$
E_{k \max }=V_{k \max }
$$

Based on equations 21 and (23), one can solve the natural frequency of cable after an added mass block is applied:

$$
\omega_{m}^{2}=\frac{E I \int_{0}^{L}\left[\phi^{\prime \prime}(x)\right]^{2} \mathrm{~d} x+T \int_{0}^{L}\left[\phi^{\prime}(x)\right]^{2} \mathrm{~d} x^{2}}{m \int_{0}^{L}[\phi(x)]^{2} \mathrm{~d} x+M\left[\phi\left(L_{m}^{\prime}\right)\right]^{2}} .
$$

Bring equations (24) into (26), one has

$$
\omega_{m}^{2}=\frac{1}{1+\left(2 M / m L_{e q}\right) \sin ^{2}\left(n L_{m}^{\prime} / L_{e q}\right)}\left(\frac{E I}{m}\left(\frac{n \pi}{L_{e q}}\right)^{4}+\frac{T}{m}\left(\frac{n \pi}{L_{e q}}\right)^{2}\right) .
$$

The natural frequency of cable before applying an added mass block is

$$
\omega^{2}=\frac{E I}{m}\left(\frac{n \pi}{L_{e q}}\right)^{4}+\frac{T}{m}\left(\frac{n \pi}{L_{e q}}\right)^{2}
$$

$$
\left(\frac{\omega_{1}}{\omega_{m 1}}\right)^{2}=1+\frac{2 M}{m L_{e q}} \sin ^{2} \frac{\pi L_{m}^{\prime}}{L_{e q}}=1+\frac{2 M}{m L_{e q}} \sin ^{2} \frac{\pi\left(2 L_{m}-L+L_{e q}\right)}{2 L_{e q}} .
$$

$\omega_{1}$ and $\omega_{m 1}$, the $1^{\text {st }}$ order of natural frequency of cable before and after added mass is applied, can be measured by instrument. The weight of an added mass $M$ and its location $L_{m}$ can also be measured and determined. Consequently, based on the $1^{\text {st }}$ order of natural frequency of cable before and after an added mass block is applied, the equivalent effective length of cable can be derived by equation (28). If the added mass block is applied at the middle of cable, which means $L_{m}=(L / 2)$, then from equation (29), one has

$$
\left(\frac{\omega_{1}}{\omega_{m 1}}\right)^{2}=1+\frac{2 M}{m L_{e q}} .
$$

Using the $1^{\text {st }}$ order of natural frequency to analyze, by comparing equations (26) and (27), one has
Or it can be written as

$$
L_{e q}=\frac{2 M}{\left[\left(\omega_{1} / \omega_{m 1}\right)^{2}-1\right] m}
$$

\section{Using Equivalent Effective Length to Identify Cable Tension Force}

Taking equivalent length $L_{e q}$ into equation (28), one can obtain the equation of cable tension force $T$, i.e.,

$$
T=m\left(\frac{\omega_{1} L_{e q}}{\pi}\right)^{2}-E I\left(\frac{\pi}{L_{e q}}\right)^{2}=\frac{16 M^{4} \omega_{1}^{2}-\left[\left(\omega_{1} / \omega_{m 1}\right)^{2}-1\right]^{4} \pi^{4} m E I}{4\left[\left(\omega_{1} / \omega_{m 1}\right)^{2}-1\right]^{2} \pi^{2} M^{2} m}
$$

The equation above is an accurate method to identify the tension force of short length cable, depending on $\omega_{1}$ and $\omega_{m 1}$, the $1^{\text {st }}$ order of natural frequency of cable before and after added mass block is applied.

\section{Practical Engineering Verification}

In order to illustrate the accuracy and applicability of the cable tension force calculation method proposed in this 
paper, three arch bridges are selected as a case study. Firstly, the pressure sensors need to be installed on the cable during bridge construction to obtain the tension force of cable, and consider this value as a reference value. Then, combined with the measured frequency, the tension force of the short cable is calculated by the method of additional mass block proposed in this paper and compared with the reference value.

5.1. Project 1. Liujing Yujiang superbridge (as shown in Figure 6) in Guangxi, which was built in 1997 and completed in 1999, is a superlarge bridge across Yujiang on Liuzhou Nanning Expressway. In 2018, it was repaired and reinforced, replacing the original $61 \varphi 7$ galvanized parallel steel wire with $55 \varphi 7$ galvanized parallel steel wire.

In the process of replacing the suspender, the no. \#4 short suspender with a length of $6.93 \mathrm{~m}$ at the upstream side is selected as the verification example of the proposed method in this paper. The new suspender adopts OVMLZM 7-55 III type PES (FD) low-stress anticorrosive cable body and adopts double-layer HDPE protection. Its strength grade is $1670 \mathrm{mpa}$, the breaking load is $3535 \mathrm{kN}$, modulus of elasticity is greater than $1.9 \times 105 \mathrm{MPa}$, the anchorage at the arch rib end adopts the cold cast anchor lzm-55, and other end adopts the anchorage form of steel tie rod and parallel steel wire connector with a ball stranding device.

After the installation of the new suspender, the lower end of the suspender is tensioned with a jack and the tension was $450 \mathrm{kN}$. Then, the cable force is identified by this method. The processes are as follows:

(1) The velocity pick-up is installed at $5 \mathrm{~m}$ from the lower end of the suspender, and the velocity timehistory curve of the suspender is obtained by means of environmental random excitation. FFT analysis is carried out on the time-history curve, and then, the obtained $1^{\text {st }}$ order frequency of the suspender is $13.36 \mathrm{~Hz}$.

(2) A $30.4 \mathrm{~kg}$ mass block (as shown in Figure 7) $2.275 \mathrm{~m}$ away from the lower end of the suspender was installed. Repeat step 1 , the $1^{\text {st }}$ order frequency of the suspender with lumped mass block is $11.41 \mathrm{~Hz}$.

(3) The effective length of the suspender could be calculated according to equation (28) whose corresponding parameters are shown in Table 1. One can obtain effective length of suspender is $5.81 \mathrm{~m}$.

Then, the cable force is $436.13 \mathrm{kN}$ by taking the effective length into equation (31), and its deviation from the actual cable force is only $3.08 \%$, which meets the requirements of the project.

5.2. Project 2. The Pumiao Bridge, shown in Figure 8 , is located in Pumiao County, Yongning District, Nanning City, and crossed the Yongjiang River. It was completed in July 1996. The main bridge is a half-through-type steel frame reinforced concrete arch bridge with a $312 \mathrm{~m}$ span. 27 suspenders are arranged for each arch rib of the main bridge.

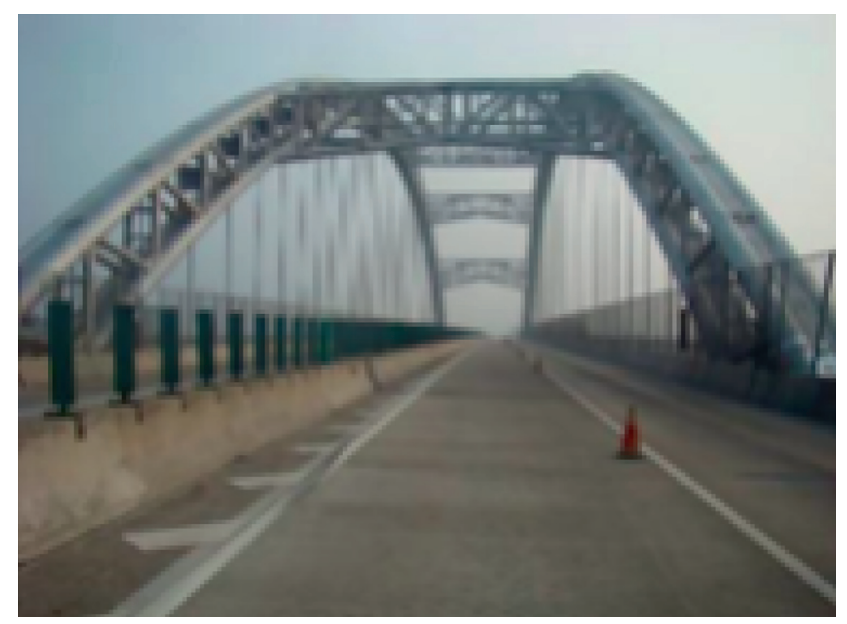

FIgURE 6: Liujing Yujiang superbridge.

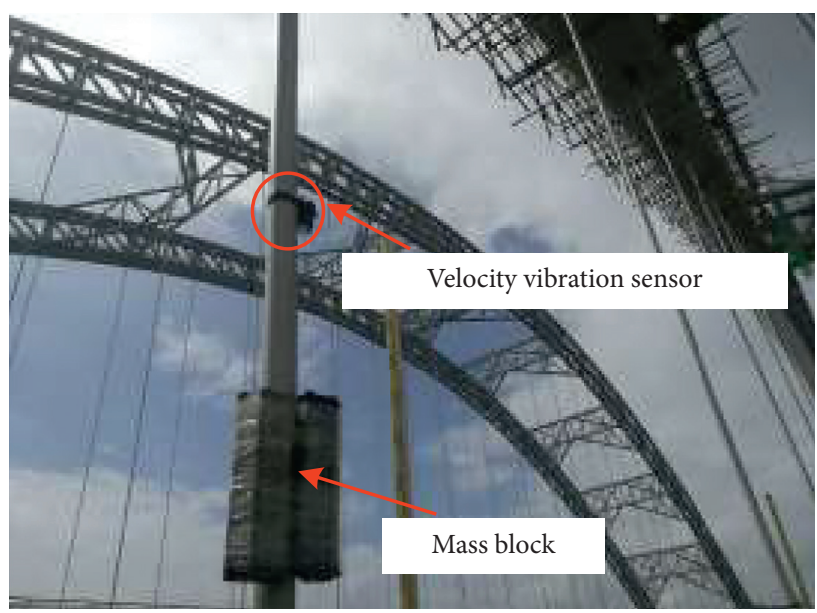

Figure 7: Field test of cable force with lumped mass.

TABle 1: Parameter table of equivalent length calculation.

\begin{tabular}{lcccccc}
\hline Parameters & $\begin{array}{c}\omega_{1} \\
(\mathrm{rad} / \mathrm{s})\end{array}$ & $\begin{array}{c}\omega_{m 1} \\
(\mathrm{rad} / \mathrm{s})\end{array}$ & $\begin{array}{c}\mathrm{M} \\
(\mathrm{kg})\end{array}$ & $\begin{array}{c}\mathrm{m} \\
(\mathrm{kg} / \mathrm{m})\end{array}$ & $\begin{array}{c}L_{m} \\
(\mathrm{~m})\end{array}$ & $\begin{array}{c}L \\
(\mathrm{~m})\end{array}$ \\
\hline Value & 13.36 & 11.41 & 30.4 & 18.43 & 2.275 & 6.93 \\
\hline
\end{tabular}

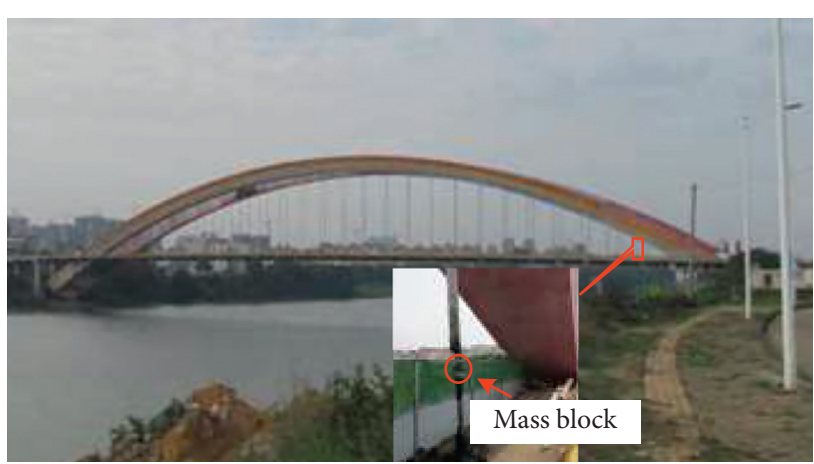

Figure 8: Pumiao Bridge. 
TABLE 2: Comparison results of cable forces.

\begin{tabular}{lccc}
\hline Position & Frequencies without mass block $(\mathrm{Hz})$ & Frequencies with mass block $(\mathrm{Hz})$ & Tensioning force $(\mathrm{kN})$ \\
\hline Upstream & 9.91 & 9.70 & 1174.51 \\
Downstream & 9.86 & 9.65 & 1185.55 \\
\hline
\end{tabular}

TABle 3: Comparison results of cable forces under different test methods.

\begin{tabular}{lcccc}
\hline \multirow{2}{*}{ Method } & \multicolumn{2}{c}{ Upstream } & \multicolumn{2}{c}{ Downstream } \\
& Cable force $(\mathrm{kN})$ & Relative deviation (\%) & Cable force (kN) & Relative deviation (\%) \\
\hline Pressure sensor method & 1174.51 & - & 1185.55 & - \\
Conventional method & 171.93 & $45.76 \%$ & 1695.18 & $42.99 \%$ \\
This paper & 1149.64 & $-2.12 \%$ & 1184.28 & $-0.11 \%$ \\
\hline
\end{tabular}

The original suspender is made of $27 \Phi 7$ high-strength steel wire wrapped with PE. Due to the cracks of PE sheath of some suspenders and the corrosion of lower anchor head, the suspenders of the whole bridge were replaced in 2018 . 1860 grade $27 \Phi 15.2 \mathrm{~mm}$ epoxy coated unbonded steel strand is selected as the new suspenders and wrapped with PE. The outer diameter of the cable body is $\Phi 126 \mathrm{~mm}$, the nominal breaking force is $7031 \mathrm{kN}$, and the unit weight of the cable body is $36.81 \mathrm{~kg} / \mathrm{m}$.

The $2^{\text {nd }}$ suspenders are typical short suspenders, of which the cable force is tested to verify the correctness of this method.

First, the acceleration signal of the suspender without mass was tested. Then, the iron block with a mass of $20.75 \mathrm{~kg}$ (as shown in Figure 8) was bound at the middle position of the suspender, and the $1^{\text {st }}$ order frequency of the cable could be obtained through FFT transformation, as shown in Table 2. Finally, the cable force of the suspender, as shown in Table 2, can be obtained by taking the frequency into equation (31). Simultaneously, the results of the cable force calculated by the conventional method are also shown in Table 3 .

It can be seen from Table 1 that, due to the constraint of the additional mass, the first-order frequency decreases to some extent. According to the comparison results in Table 2, one can see the following: (1) there is a large deviation between the cable force identified by the conventional method and the actual cable force, and the upstream and downstream errors are $45.76 \%$ and $42.99 \%$, respectively, which cannot meet the engineering requirements. (2) The upstream and downstream cable force errors identified by the method in this paper are very small, i.e., $-2.12 \%$ and $-0.11 \%$, respectively, which can meet the engineering requirements.

5.3. Project 3. Yuanjiang Bridge in Wuzhou is a 3-span halfthrough concrete-filled steel tubular tied arch bridge (as shown in Figure 9). It is $695 \mathrm{~m}$ long and $25.6 \mathrm{~m}$ wide. The span composition of the main bridge is $(40+175+40) \mathrm{m}$, and the rise height is $43.75 \mathrm{~m}$. The length of the $5^{\text {th }}$ suspender is $10.38 \mathrm{~m}$, tensile stiffness is $109.76 \mathrm{kN}$, and cable unit length mass is $20.88 \mathrm{~kg} / \mathrm{m}$.

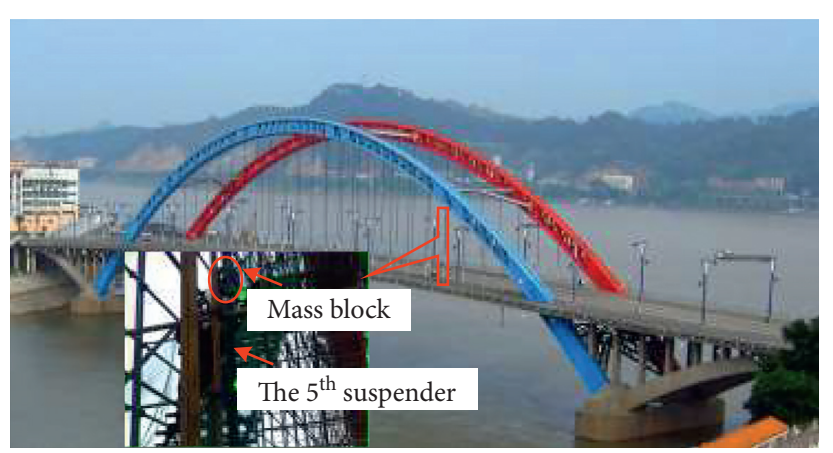

Figure 9: Yuanjiang Bridge.

When installing the $5^{\text {th }}$ suspender (shown in Figure 9), the method in this paper is verified. Firstly, the acceleration pick-up is installed at the position $3 \mathrm{~m}$ away from the anchor head below. The acceleration signal of the suspender is tested, as shown in Figure 10(a), and the $1^{\text {st }}$ order frequency of the cable is $13.497 \mathrm{~Hz}$ through FFT transformation (shown in Figure 10(b)). Then, the iron block with a weight of $20.75 \mathrm{~kg}$ is bound at the middle position of the suspender (as shown in Figure 9) to simulate the concentrated mass block. The collected acceleration signal is as shown in Figure 11(a), and the first-order frequency is $12.087 \mathrm{~Hz}$ through spectrum analysis of acceleration signal, as shown in Figure 11(b).

Finally, the effective length of the suspender could be calculated according to equation (29) which corresponding parameters are shown in Table 4 . It can be obtained that an effective length of suspender is $8.06 \mathrm{~m}$. The cable forces of the suspender can be obtained by taking the frequencies into equation (32). Simultaneously, the accurate cable force value of the suspender is obtained by the pressure sensor installed at the anchor head, and the cable force calculated by the conventional calculation method is also shown in Table 5, respectively.

From the data in Table 5, it can be seen that the cable force value obtained by the conventional method has a great error with the actual cable force value, reaching $72.45 \%$, while by the method in this paper, the test accuracy can reach within $5 \%$, meeting the engineering requirements. 


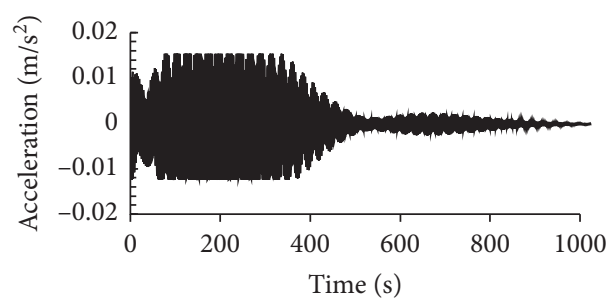

(a)

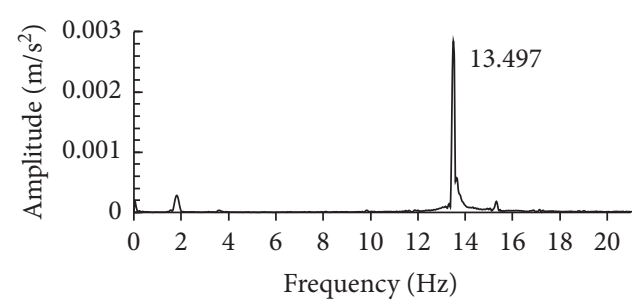

(b)

FIgURe 10: (a) Acceleration time-history curve of suspender without additional mass; (b) frequency spectrum without additional mass.

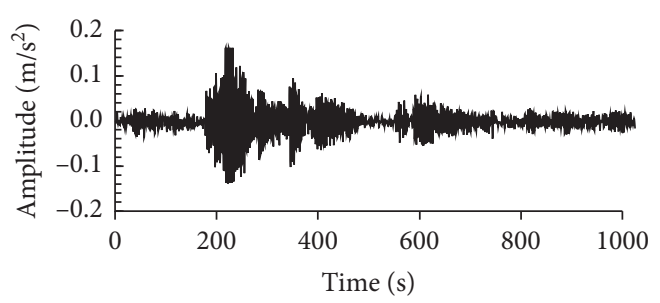

(a)

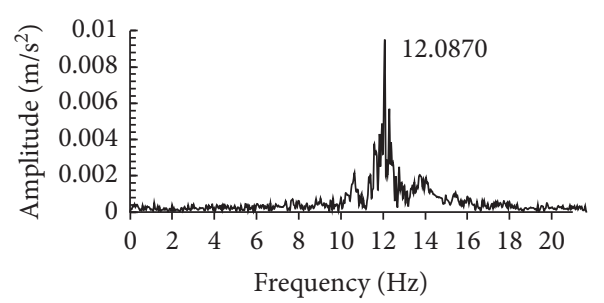

(b)

FIGURE 11: (a) Acceleration time-history curve of suspender with additional mass; (b) frequency spectrum with additional mass.

TABle 4: Parameters table of equivalent length calculation.

\begin{tabular}{lcccccc}
\hline Parameters & $\begin{array}{c}\omega_{1} \\
(\mathrm{rad} / \mathrm{s})\end{array}$ & $\begin{array}{c}\omega_{m 1} \\
(\mathrm{rad} / \mathrm{s})\end{array}$ & $\begin{array}{c}\mathrm{M} \\
(\mathrm{kg})\end{array}$ & $\begin{array}{c}\mathrm{m} \\
(\mathrm{kg} / \mathrm{m})\end{array}$ & $\begin{array}{c}L_{m} \\
(\mathrm{~m})\end{array}$ & $\begin{array}{c}L \\
(\mathrm{~m})\end{array}$ \\
\hline Value & 13.497 & 12.087 & 20.75 & 20.88 & 5.19 & 10.38 \\
\hline
\end{tabular}

TABLE 5: Comparison results of cable forces.

\begin{tabular}{lcc}
\hline Method & Force $(\mathrm{kN})$ & Relative deviation (\%) \\
\hline Pressure sensor method & 935.00 & - \\
Conventional method & 1612.39 & 72.45 \\
This paper & 974.59 & 4.23 \\
\hline
\end{tabular}

\section{Conclusion}

Considering that the traditional frequency method has a large error in calculating short cable tension force, this paper presented a novel calculation method to improve the accuracy of the results. Firstly, the identification method of the effective cable length considering the mass block was deduced, and combined with the natural frequency, the calculation equation of the short cable force was established. Then, three practical projects were used to illustrate the analysis process of the proposed method. The following conclusions are drawn:

(1) Since the bending stiffness and boundary conditions have a greater impact on the accuracy of the short cable tension force measurement, the concept of equivalent effective length is presented to consider the influence. By installing two dampers on the cable to simulate the change in boundary conditions, the vibration equation of the cable is established. Then, the equivalent effective length of shore cable can be obtained through the RITZ method and the principle of constant natural frequency.

(2) In order to effectively and accurately identify the equivalent effective length of short cable, a mass block is installed at a certain position from the anchor cap on the cable. Then, the equivalent effective length identification method considering the mass block is deduced. Combining the natural frequency and the deduced effective length, a novel measurement method of the short cable tension force considering the mass block is proposed.

(3) Three suspender arch bridges are selected as case study. The velocity vibration sensor and the mass block are, respectively, installed on the tested short cable, and the time-history vibration signals collected can be converted into the natural frequency of the short cable through FFT transformation. The conventional method and the new method proposed in this paper are used to calculate the short cable tension force, respectively. By comparing with the theoretical cable tension force obtained by the pressure sensor method, the maximum relative error obtained by the method proposed in this paper is $3.08 \%,-2.12 \%$, and $4.23 \%$, respectively, which has high accuracy and reliability.

\section{Data Availability}

The data used to support the findings of this study are included within the article. 


\section{Conflicts of Interest}

The authors declare that they have no conflicts of interest.

\section{Acknowledgments}

This research was sponsored by the Nanning Excellent Young Scientist Program (no. RC20180108), Nanning Excellent Young Scientist Program and Guangxi Beibu Gulf Economic Zone Major Talent Program (no. RC20190206), Science and Technology Base and Talent Special Project of Guangxi Province (no. AD19245152), and "Yongjiang Plan" of Nanning Leading Talents in Innovation and Entrepreneurship (no. 2018-01-04).

\section{References}

[1] Q. Guo, L. Li, Y. Cheng, Y. Jiao, and C. Xu, "Laboratory evaluation on performance of diatomite and glass fiber compound modified asphalt mixture," Materials \& Design (1980-2015), vol. 66, no. 66, pp. 51-59, 2015.

[2] H. B. Liu, H. Wang, G. J. Tan et al., "Effect of temperature and spring-mass systems on modal properties of Timoshenko concrete beam," Structural Engineering and Mechanics, vol. 65, no. 4, pp. 389-400, 2018.

[3] Q. Guo, Y. Bian, L. Li, Y. Jiao, J. Tao, and C. Xiang, "Stereological estimation of aggregate gradation using digital image of asphalt mixture," Construction and Building Materials, vol. 94, no. 94, pp. 458-466, 2015.

[4] L. Wang, H. Wang, L. Li, T. Hao, and C. Wu, "An adjustment method for the suspender tension of CFSTTTHAB based on influence matrix of single suspender," Advances in Civil Engineering, vol. 2020, no. 6, pp. 1-10, 2020.

[5] Q. L. Guo, Q. Liu, P. Zhang, Y. Gao et al., "Temperature and pressure dependent behaviors of moisture diffusion in dense asphalt mixture," Construction and Building Materials, vol. 2020, no. 246, Article ID 118500.

[6] Seaoc, Conceptual Framework for Performance-Based Seismic Design, pp. 393-416, Structural Engineers Association of California, 1996.

[7] K.-S. Kim and H. S. Lee, "Analysis of target configurations under dead loads for cable-supported bridges," Computers \& Structures, vol. 79, no. 29-30, pp. 2681-2692, 2001.

[8] J. R. Casas, "A combined method for measuring cable forces: the cable-stayed alamillo bridge, Spain," Structural Engineering International, vol. 4, no. 4, pp. 235-240, 1994.

[9] S. Kangas, A. Helmicki, V. Hunt, R. Sexton, and J. Swanson, "Cable-stayed bridges: case study for ambient vibration-based cable tension estimation," Journal of Bridge Engineering, vol. 17, no. 6, pp. 839-846, 2012.

[10] W. Y. Liao, Y. Q. Ni, and G. Zheng, "Tension force and structural parameter identification of bridge cables," Advances in Structural Engineering, vol. 15, no. 6, pp. 983-995, 2012.

[11] A. C. Marcelo and A. P. Carlos, "Determination of the axial force on stay cables accounting for their bending stiffness and rotational end restraints by free vibration tests," Journal of Sound and Vibration, vol. 317, no. 1-2, pp. 127-141, 2008.

[12] Y. Q. Ni, J. M. Ko, and G. Zheng, "Dynamic analysis of largediameter sagged cables taking into account flexural rigidity," Journal of Sound and Vibration, vol. 257, no. 2, pp. 301-319, 2002.
[13] A. B. Mehrabi and H. Tabatabai, "Unified finite difference formulation for free vibration of cables," Journal of Structural Engineering, vol. 124, no. 11, pp. 1313-1322, 1998.

[14] H. Zui, T. Shinke, and Y. Namita, "Practical formulas for estimation of cable tension by vibration method," Journal of Structural Engineering, vol. 122, no. 6, pp. 651-656, 1996.

[15] A. B. Mehrabi and H. Tabatabai, "Unified finite difference formulation for free vibration of cables," Journal of Structural Engineering, vol. 124, no. 11, pp. 1313-1322, 1998.

[16] Z. Fang and J.-q. Wang, "Practical formula for cable tension estimation by vibration method," Journal of Bridge Engineering, vol. 17, no. 1, pp. 161-164, 2012.

[17] H. Zui, Y. Hamazaki, and Y. Namita, "Study on tension and flexual rigidity identification for cables having large ratio of the diameter and the length," Doboku Gakkai Ronbunshu, no. 703, pp. 141-149, 2002.

[18] G. Roman, D. R. Guido, and P. Johannes, "Cable force determination for the Danube channel bridge in Vienna," Structural Engineering International, vol. 15, no. 3, pp. 181$185,2005$.

[19] B. H. Kim and T. Park, "Estimation of cable tension force using the frequency-based system identification method," Journal of Sound and Vibration, vol. 304, no. 3-5, pp. 660-676, 2007.

[20] T. Park, D. Hyung Lee, and B. Hwa Kim, "Estimation of tension force in double hangers by a system identification approach," Inverse Problems in Science and Engineering, vol. 18, no. 2, pp. 197-216, 2010.

[21] P. Kyu-Sik, S. Taek-Ryong, and N. Myung-Hyun, "Feasibility study on tension estimation technique for hanger cables using the FE model-based system identification method," Mathematical Problems in Engineering, vol. 2015, Article ID 512858, 12 pages, 2015.

[22] B. Yan, J. Yu, and M. Soliman, "Estimation of cable tension force independent of complex boundary conditions," Journal of Engineering Mechanics, vol. 141, no. 1, 2014.

[23] H. A. M. Z. S. Ehsan, M. Norouzi, R. Allemang et al., "Vibration-based cable condition assessment: a novel application of neural networks," Engineering Structures, vol. 177, pp. 291-305, 2018. 